\title{
A industrialização da pauta de exportação brasileira entre 1964 e 1974: novos dados e índices para o comércio exterior brasileiro do período
}

\author{
JORGE CHAMI BATISTA \\ WILSON CALMON ALMEIDA DOS SANTOS*
}

\begin{abstract}
The industrialization of the Brazilian exports regulation between 1964 and 1974: new data and indexes for the foreign trade commerce in the period. This paper analyses the effects on Brazil's trade indices of the rising share of industrial products in Brazil's exports in the period from 1964 to 1974. New price and quantity indices of Fisher for Brazil's exports and imports of industrial and non-industrial goods have been especially constructed for this period, in order to obtain methodologically consistent series of indexes from 1964 to 2005. The marketshare-constant model was applied to analyze the effects of different groups of products on Brazil's export revenues between 1964 and 1974.

Key-words: primary products; manufactured products; market-share-constant model; terms of trade; price and quantity indexes of Brazilian exports.

JEL: F14, O14.
\end{abstract}

\section{INTRODUÇÃO}

O período que vai de 1964 até 1974 já foi intensamente estudado pela literatura sobre a economia brasileira. Os primeiros anos do período foram marcados por políticas de estabilização da economia e por importantes reformas, particularmente, nos mercados financeiro e do trabalho. A partir de 1968, houve um vigoroso e duradouro crescimento da produção industrial do país, que se mantém único na nossa história econômica. A política econômica teve importantes efeitos na composição e na dinâmica do comércio exterior brasileiro, dando

\footnotetext{
"Professor Adjunto do Instituto de Economia da UFRJ (e-mail: jchami@uol.com.br); e Bolsista de Iniciação Científica do CNPq e graduando do Instituto de Economia da UFRJ (e-mail: calmonwilson@gmail.com). Submetido: março de 2006; Aceito: julho 2006.
} 
início ao processo de industrialização das exportações brasileiras. No cenário mundial, os últimos anos do sistema monetário criado em Bretton Woods e os primeiros anos do atual sistema de taxas de câmbio flutuantes foram marcados por grande liquidez internacional, gerando substancial aumento da demanda mundial e dos preços internacionais das commodities. ${ }^{1}$

A análise dos efeitos da industrialização da pauta de exportação sobre os índices de comércio exterior enfrentava algumas dificuldades devido à ausência de índices por fator agregado e à incompatibilidade metodológica entre as séries disponíveis para o período 1964-1974 e as que cobrem o período 1974-2005. ${ }^{2}$

O principal objetivo deste artigo é preencher essa importante lacuna, fazendo uso de um conjunto inédito de séries de índices de Fisher para o comércio exterior brasileiro do período entre 1964 e 1974, e, através do uso de novos dados digitalizados e desagregados por produto sobre o comércio internacional do período, aplicar o conhecido modelo de Market Share Constante, quantificando os efeitos demanda, produto e competitividade para as exportações brasileiras entre 1964 e 1974.

Além desta introdução, este artigo está dividido em cinco seções. Na primeira seção, descrevem-se a metodologia, as limitações e a qualidade das novas séries para o comércio exterior brasileiro no agregado. $\mathrm{Na}$ segunda seção, analisa-se o papel das exportações de produtos manufaturados nos índices de exportação. O modelo de Market Share Constante é descrito na terceira seção e seus resultados são apresentados na quartaseção. Na quinta seção, tecem-se algumas considerações finais.

\section{NOVOS ÍNDICES DE COMÉRCIO EXTERIOR DO BRASIL: 1964-1974}

Para construir os índices foram utilizados, fundamentalmente, os dados de comércio de produtos classificados segundo a Revisão 1 da Classificação de Comércio Internacional Padrão (CCIP-1), a cinco dígitos, da base de dados das Nações Unidas. ${ }^{3}$

Para construir as séries de índices de exportação de produtos classificados por fator agregado (i.e., básicos, semi-manufaturados e manufaturados), inéditas para o período 1964-1974, substituímos alguns poucos produtos, de grande im-

\footnotetext{
${ }^{1}$ No caso especial do petróleo, esse cenário permitiu a quadruplicação dos seus preços em 1973, com enormes repercussões para a economia internacional, muito particularmente para economias como a do Brasil, dependentes de importações do produto.

${ }^{2}$ As tentativas de encadear e obter séries que cubram todo o século XX esbarram na mesma dificuldade; ver BATISTA, Jorge Chami, O Setor Externo Brasileiro no Século XX, Em: Estatísticas do Século XX, Centro de Documentação e Disseminação de Informações, Instituto Brasileiro de Geografia e Estatísticas - IBGE; Rio de Janeiro, 2003.

${ }^{3}$ Os dados da COMTRADE (Commodity Trade Statistics Database) das Nações Unidas, segundo o padrão SITC - Revisão 1 (Standard International Trade Classification - Revision 1) a cinco dígitos, estão digitalizados e encontram-se em http://unstats.un.org/unsd/.
} 
portância na pauta de exportação brasileira, de sua classificação CCIP-1 pelos seus equivalentes na Nomenclatura Aduaneira de Bruxelas (NAB-5dígitos), adotada no Brasil até 1970, e na Nomenclatura Brasileira de Mercadorias (NBM-8 dígitos), adotada a partir de 1971 .

Assim como os atuais índices de comércio exterior, os índices anuais para o período entre 1964 e 1974 foram calculados segundo o método de Fisher, sendo os índices de preços calculados de forma direta e os de quantidade, implícitos. ${ }^{4}$ Adotou-se uma base móvel e uma crítica automática para os dados, eliminandose $5 \%$ dos produtos de cada uma das caudas da distribuição da variação de preços entre cada par de anos consecutivos ${ }^{5}$. O número de produtos utilizados aumentou de 465 entre 1964/65 para 767 entre 1973/74, no caso das exportações, e de 659 para 974 nos mesmos períodos, no caso das importações. Com base nesses critérios, atingiu-se um grau de cobertura médio de $96 \%$ e mínimo de $93 \%$ para as exportações no período entre 1964 e 1974. Para as importações, a cobertura média ficou entre $90 \%$ e $96 \% .^{6}$

As séries de índices de comércio exterior do Brasil mais utilizadas até aqui na literatura econômica, para o período entre 1964 e 1974, eram as calculadas pela FGV-RJ e publicadas na Revista Conjuntura Econômica (CE-FGV). Tais séries, baseadas em índices diretos de quantidade de Laspeyres com base móvel e índices implícitos de preços, contavam, em 1960, com uma amostra de 92 produtos de exportação e 345 produtos de importação, o que daria uma cobertura de $95 \%$ para as exportações e $92 \%$ para as importações. ${ }^{7}$ Em 1980, a amostra envolvia cerca de 400 produtos e a cobertura variava entre $90 \%$ e $95 \%$. O grau de cobertura e o número de produtos incluídos nas nossas novas amostras são mais elevados que os da CE-FGV. Assim, acreditamos que nossas estimativas sejam qualitativamente superiores às encontradas pela CE-FGV.

\footnotetext{
${ }^{4}$ As séries de quantidade e preços das exportações e importações brasileiras a partir de 1974 são calculadas pela FUNCEX e divulgadas pelo IPEA (http://www.ipeadata.gov.br) em bases mensais e anuais através de índices de Fisher diretos para preços e implícitos para quantidades. Elas fizeram uso da Nomenclatura Brasileira de Mercadorias (NBM) a 8 dígitos até 1988, 10 dígitos até 1996, e da Nomenclatura Comum do Mercosul (NCM) a 8 dígitos a partir de 1997. Ver GUIMARÃES, Eduardo Augusto; PINHEIRO, Armando Castelar; FALCÃO, Carmen; POURCHET, Henry; MARKWALD, Ricardo Andrés “Índices de Preços e Quantum das Exportações Brasileiras”, Texto para Discussão 121, Fundação Centro de Estudos do Comércio Exterior — FUNCEX, versão atualizada, 11p., Rio de Janeiro, abril de 1997.

${ }^{5}$ A exceção ficou por conta das importações de petróleo bruto entre 1973 e 1974, que foram mantidas nos cálculos embora devessem ser eliminadas pelo critério geral. Esse procedimento é idêntico ao aplicado pela FUNCEX, que também elimina os produtos abaixo do percentil $5 \%$ e acima do percentil 95\% da distribuição, ver GUIMARÃES et al. (1997).

${ }^{6} \mathrm{O}$ grau de cobertura foi calculado pela razão entre a soma dos valores das amostras a cada par de anos consecutivos e a soma dos valores totais dos mesmos anos. É interessante notar que, mesmo com os cortes, a cobertura foi significativamente alta.

${ }^{7}$ Lamentavelmente, as memórias de cálculos das séries da CE-FGV não foram encontradas nem na FGV-RJ, nem no IBGE. Desse modo, não é claro qual era exatamente o grau de cobertura das amostras a cada ano. Ver: GONÇALVES, Reinaldo. "Índices de Comércio Exterior do Brasil", Revista Brasileira de Estatística, volume 42, no. 168, p.p.331-362, out./dez. 1981.
} 
Os novos índices quantum para as exportações e importações no período entre 1964 e 1974 revelam que as estimativas da CE-FGV subestimaram as taxas de crescimento das quantidades exportadas e importadas pelo Brasil neste período. ${ }^{8}$ Os índices de Fisher, quando comparados aos índices que existem para o período posterior ao ano de 1974, tornam evidente a excepcionalidade do período 1964-74. A taxa de crescimento das quantidades exportadas nesse período foi a mais alta comparada a qualquer outro período de dez anos consecutivos entre 1964 e 2005 . Nas importações, a taxa de crescimento entre 1964 e 1974 só foi inferior às obtidas nos períodos de dez anos findos em 1975 (16,9\% a.a.) e 1998 (17,7\% a.a.).

A análise dos índices diretos de preço de Fisher revela que os preços de exportação acompanharam os preços de importação até 1973, mantendo os termos de troca em nível relativamente elevado. ${ }^{9}$

\section{O PAPEL DOS MANUFATURADOS NOS ÍNDICES DE EXPORTAÇÃO}

O Gráfico 1 revela, em escala logarítmica, os índices diretos de Fisher para os preços das exportações brasileiras por fator agregado. ${ }^{10} \mathrm{O}$ índice de preço dos produtos manufaturados aumentou em média 5,6\% ao ano entre 1964 e 1974, abaixo dos $6,2 \%$ ao ano dos produtos básicos. Porém, os preços que mais subiram foram os dos semi-manufaturados (taxa média de 11,2\% ao ano). De fato, o período é marcado por fortes altas nos preços internacionais de commodities, sobretudo nos metais. Em 1974, os preços dos nossos semi-manufaturados subiram $70,6 \%{ }^{11}$, ante um aumento de $30,2 \%$ no índice de preço agregado.

\footnotetext{
${ }^{8}$ Nas novas séries para o período 1964-1974, a taxa de crescimento do índice implícito de quantum de Fisher foi de $10,0 \%$ ao ano para as exportações e de $16,7 \%$ para as importações. Essas taxas são naturalmente inferiores às do índice direto de Laspeyres de 10,5\% para as exportações e de 18,6\% para as importações. Contudo, tais taxas são superiores aos 9,5\% e 15,9\% das exportações e importações, respectivamente, determinados pelo quantum direto de Laspeyres da CE-FGV. Todas as taxas de crescimento neste trabalho foram calculadas ajustando-se uma reta aos valores anuais em logaritmo.

${ }_{9}^{9}$ De fato, a média móvel de cinco anos dos termos de troca tem um pico em 1973 que, em todo o período entre 1968 e 2005, só perde para 1977, quando o preço do café no mercado internacional sofreu uma alta extraordinária. Os termos de troca estimados anteriormente pela CE-FGV, embora rigorosamente não pudessem ser comparados com as séries da FUNCEX, não alteram significativamente essa análise. Contudo, os índices implícitos de preços de Laspeyres da CE-FGV de exportações e importações estavam ambos superestimados em relação aos novos índices implícitos de preços de Laspeyres.

${ }^{10}$ Embora a Secretaria de Comércio Exterior tenha as séries em dólares das exportações por fator agregado desde 1964, não há tabelas de conversão da NAB, NBM a oito dígitos, ou SITC-Revisão 1 para essa classificação por fator agregado. Sendo assim, tivemos que partir da atual tabela de conversão da NCM a oito dígitos até chegar a SITC Revisão 1.

${ }^{11}$ Taxa quase idêntica aos 70,2\% de aumento dos preços dos metais (SITC 67 e 68) exportados pelo país.
} 
Contudo, olhando o período todo, de 1964 até 2005, verifica-se que o índice de preço dos produtos manufaturados cresceu $3,4 \%$ ao ano, mais rapidamente do que os 2,8\% dos semi-manufaturados e os $2,5 \%$ dos produtos básicos. ${ }^{12}$ Portanto, a industrialização da pauta de exportação do Brasil teve um efeito de longo prazo positivo sobre o índice de preços de exportação do país.

O gráfico 2 mostra que os índices de preços dos produtos manufaturados tenderam, em geral, a serem menos voláteis do que os de produtos básicos e semi-manufaturados no período entre 1964 e 2005 . Deste modo, a industrialização da pauta contribuiu para reduzir a volatilidade dos nossos preços de exportação.

A tabela 1 mostra o crescimento dos índices de quantum das exportações brasileiras por fator agregado para diversos períodos selecionados: a taxa de crescimento para os produtos manufaturados foi quase duas vezes e meia superior à do quantum total exportado pelo Brasil entre 1964 e 1974. Desempenho semelhante ocorreu no período entre 1974 e 1981, quando o quantum das exportações de manufaturados continuou crescendo a uma taxa média superior a duas vezes a do total das exportações brasileiras de mercadorias. Esse desempenho contrasta com o do período a partir de 1981, quando as quantidades exportadas de produtos manufaturados passaram a crescer a taxas médias próximas às das quantidades totais. De fato, entre 1981 e 1989 , o quantum das exportações de manufaturados aumentou bem mais que o dos produtos básicos, porém menos que o dos semi-manufaturados. Mas entre 1989 e 2005, a taxa de crescimento médio do quantum de produtos básicos foi superior à do quantum de manufaturados.

Portanto, verifica-se que o extraordinário crescimento das exportações brasileiras de mercadorias no período entre 1964 e 1981, e muito especialmente entre 1964 e 1974, foi amplamente liderado pela expansão do quantum de produtos manufaturados. Essa liderança está basicamente concentrada nesse período. ${ }^{13}$

Resta agora avaliar a contribuição dos produtos manufaturados para a receita das exportações no período entre 1964 e 1974 com o uso do conhecido modelo de Market Share Constante.

\section{O MODELO DE MARKET SHARE CONSTANTE}

O modelo de Market Share Constante (MSC) decompõe a variação das exportações em um determinado intervalo de tempo $\left(\mathrm{X}^{\mathrm{t}}-\mathrm{X}^{\mathrm{t}-1}\right)$ em três efeitos prin-

\footnotetext{
${ }^{12}$ Deve-se ressaltar que essa comparação não era rigorosamente possível anteriormente a este trabalho, pois não se dispunha de índices de preços e quantidades por fator agregado para o período entre 1964 e 1974.

${ }^{13}$ Calculando-se a taxa de crescimento das quantidades exportadas de produtos manufaturados dos últimos cinco anos a cada ano, observa-se que essa taxa qüinqüenal teve um pico em 1973, atingindo $32,5 \%$ ao ano, a maior de todo o período 1964-2005.
} 
cipais: efeito demanda, efeito produto e efeito competitividade. Esses três efeitos são mostrados no lado direito da identidade (1) abaixo:
(1)

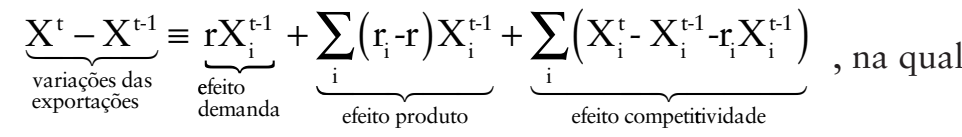
(2) $r_{i}=\frac{\left(M_{i}^{t}-M_{i}^{t-1}\right)}{M_{i}^{t-1}} \quad$ e (3) $\quad r=\frac{\left(M^{t}-M^{t-1}\right)}{M^{t-1}}$

(respectivamente, a taxa de crescimento das importações mundiais do produto $i$ e a taxa de crescimento das importações mundiais totais entre $t-1$ e $t$ ).

$\mathrm{O}$ efeito produto reflete em que medida a variação no valor exportado pelo país pode ser atribuída à concentração de suas exportações em produtos para os quais as importações mundiais estão crescendo mais ou menos rapidamente que o crescimento do comércio mundial.

Alternativamente, podemos passar o efeito demanda para o lado esquerdo da identidade (1) e substituir as taxas de crescimento das importações com base nas equações (2) e (3):

(4) $\left(\frac{\mathrm{X}^{\mathrm{t}}}{\mathrm{M}^{\mathrm{t}}}-\frac{\mathrm{X}^{\mathrm{t}-1}}{\mathrm{M}^{\mathrm{t}-1}}\right) \mathrm{M}^{\mathrm{t}} \equiv \underbrace{\sum_{\mathrm{i}=1}\left[\mathrm{X}_{\mathrm{i}}^{\mathrm{t}-1}\left(\frac{\mathrm{M}_{\mathrm{t}}^{\mathrm{i}}}{\mathrm{M}_{\mathrm{i}}^{\mathrm{t}-1}}-\frac{\mathrm{M}^{\mathrm{t}}}{\mathrm{M}^{\mathrm{t}-1}}\right)\right]}_{\text {efeito produto }}+\underbrace{\sum_{\mathrm{i}=1}\left[\left(\frac{\mathrm{X}_{\mathrm{i}}^{\mathrm{t}}}{\mathrm{M}_{\mathrm{t}}^{\mathrm{t}}}-\frac{\mathrm{X}_{\mathrm{i}}^{\mathrm{t}-1}}{\mathrm{M}_{\mathrm{i}}^{\mathrm{t}-1}}\right) \mathrm{M}_{\mathrm{i}}^{\mathrm{t}}\right]}_{\text {efeito competitividade }}$

Do lado esquerdo da igualdade temos o valor a mais ou a menos em relação ao que o país deveria ter exportado no período final para manter sua participação nas importações mundiais totais (macro share) constante. $\mathrm{O}$ efeito competitividade reflete em que medida os ganhos (perdas) do macro share do país são atribuídos aos ganhos (perdas) de participação nas importações mundiais de cada produto (micro shares).

$\mathrm{Na}$ identidade (4), o efeito produto pondera a variação nas participações de cada produto nas importações mundiais pelo valor das exportações do país no período inicial, como no índice de Laspeyres. O efeito competitividade pondera a variação no market share do país em cada produto pelo valor das importações mundiais no período final, como no índice de Paasche. Caso ambos os efeitos fossem ponderados por valores do período inicial, um terceiro efeito residual apareceria na identidade igual à soma dos produtos entre os micro shares e as variações nas importações mundiais de cada produto:

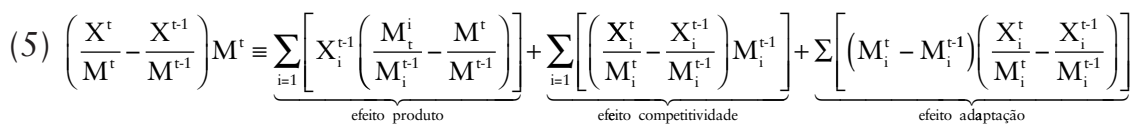


Fagerberg e Sollie (1987:1575) mostraram que esse terceiro efeito, chamado de adaptação relativa, reflete em que medida o país exportador teve sucesso em adaptar a sua pauta de exportação às mudanças na composição por produto do mercado mundial de importações. ${ }^{14}$

\section{RESULTADOS DO MODELO PARA 1964/65-1973/74}

O modelo de market share constante foi aplicado à participação das exportações do Brasil nas importações mundiais, considerando o valor médio das exportações brasileiras e das importações mundiais nos anos de 1964 e 1965 (período inicial) e nos anos de 1973 e 1974 (período final). ${ }^{15}$

Os resultados do modelo são apresentados na tabela 2. Observa-se que os efeitos demanda e competitividade foram positivos, porém, o efeito produto foi negativo para o total das exportações brasileiras. ${ }^{16} \mathrm{O}$ efeito competitividade positivo mais que compensou o efeito produto negativo, de tal forma que, em 1973/74, as exportações brasileiras cresceram US\$ 937 milhões (62\% das exportações brasileiras no período inicial) acima do que seria necessário para manter constante o market share do Brasil. O efeito adaptação relativa respondeu por $74 \%$ do efeito competitividade de Paasche. O restante deveu-se ao efeito Laspeyres.

Subdividindo-se esses efeitos pelas exportações brasileiras classificadas por fator agregado, verifica-se que os produtos básicos foram os grandes responsáveis pelo efeito produto negativo. De fato, para os produtos básicos, o efeito competitividade positivo não foi suficiente para compensar o efeito produto negativo, levando à redução do market share do Brasil no total dos produtos básicos .

Por outro lado, as importações de manufaturados exportados pelo Brasil cresceram acima da média das importações mundiais totais, gerando um efeito produto positivo. Como os ganhos de competitividade dos produtos manufaturados brasileiros foram da mesma magnitude dos ganhos dos produtos básicos, mas muito superiores em relação aos valores exportados nessas duas categorias,

\footnotetext{
${ }^{14}$ A adaptação é relativa, pois o efeito será zero quando o país muda sua pauta de exportação na mesma taxa que a média de todos os países exportadores para o mercado. Ver FAGERBERG, Jan e SOLLIE, Gunnar. "The method of constant market shares analysis reconsidered", Applied Economics, 1989,19, p.1571-1583.

${ }^{15}$ Utilizou-se mais uma vez a classificação SITC, Revisão 1, a quatro e cinco dígitos da base de dados Comtrade das Nações Unidas. Foram incluídos um total de 362 produtos, sendo 294 a 3, 4 e 5 dígitos, correspondentes aos principais produtos de exportação do Brasil no período, e 68 resíduos dos grupos a 1, 2, 3 e 4 dígitos, de modo a cobrir o total das exportações brasileiras e das importações mundiais nos dois períodos.

${ }^{16}$ Caso o efeito produto fosse zero (se os mercados de importação por produto exportado pelo Brasil tivessem crescido à mesma taxa das importações mundiais totais) as nossas exportações teriam crescido $538 \%$, e não os $368 \%$ efetivamente observados.
} 
foram os manufaturados os principais responsáveis pelo crescimento das nossas exportações a uma taxa superior à das importações mundiais.

Vale lembrar que os efeitos produto negativos dos produtos básicos e semimanufaturados ocorreram a despeito da substancial elevação dos preços desses produtos no período. Isso significa que a demanda mundial por esses produtos diminuiu relativamente a demanda por produtos manufaturados.

Examinando-se as principais indústrias exportadoras, observa-se que o efeito produto foi negativo para os conjuntos de manufaturados da agroindústria e da indústria têxtil. ${ }^{17}$ Os principais responsáveis pelo efeito produto positivo dentre os manufaturados foram os bens de capital. Quanto ao efeito competitividade positivo, os maiores destaques foram as indústrias de alimentos (café solúvel, sucos de frutas, carnes industrializadas etc.), têxteis, vestuário, calçados e bens de capital.

\section{CONSIDERAÇÕES FINAIS}

A industrialização da pauta de exportações brasileiras teve efeito positivo sobre o volume e sobre as receitas de exportação no período entre 1964 e 1974. No longo prazo, o efeito sobre o índice de preços de exportação também tem sido positivo, melhorando os termos de troca e reduzindo a volatilidade desse índice.

O efeito produto negativo dos produtos básicos e primários de exportação do Brasil, que reflete a ausência de dinamismo das importações mundiais desses produtos, ocorreu mesmo no período entre 1964 e 1974, a despeito do substancial aumento nos preços dos produtos baseados em recursos naturais nesse período. A ausência de dinamismo das importações mundiais desses produtos tem sido constatada para diversos períodos desde a década de 70. No entanto, isso não significa que a industrialização da pauta de exportação deva ser feita a qualquer custo. A especialização em manufaturados não baseados em recursos naturais não é garantia de exportações dinâmicas, e a especialização em um subconjunto de produtos baseados em recursos naturais pode ser dinâmica. ${ }^{18}$

Gráfico 1: Índice direto de preços de Fisher das exportações brasileiras (em log)

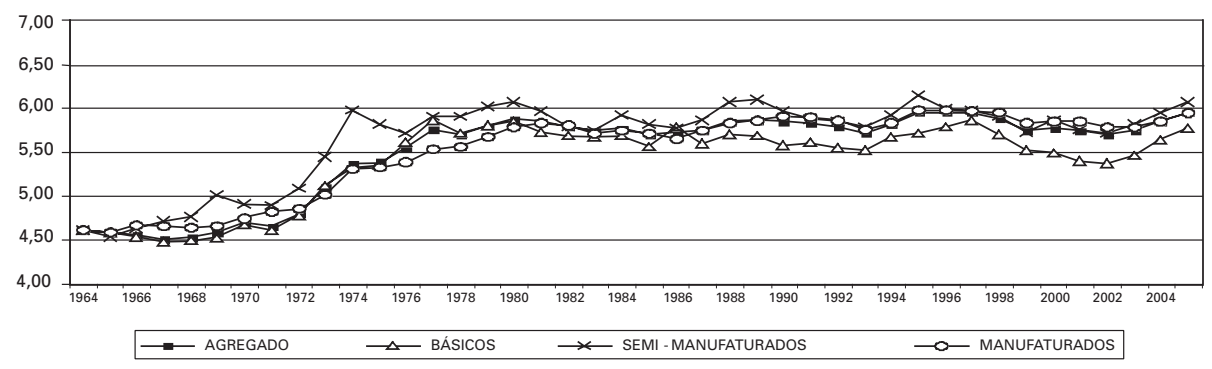

\footnotetext{
${ }^{17}$ SITC de 0 a 4 e SITC 65, respectivamente.

${ }^{18}$ Ver, por exemplo, BATISTA, Jorge Chami, "Latin American export specialization in resource-based products: implications for growth", The Developing Economies.
} 
Gráfico 2: Volatilidade dos preços de exportações por valor agregado (coeficiente de variação $=$ desvio padrão/média) para períodos de 10 anos

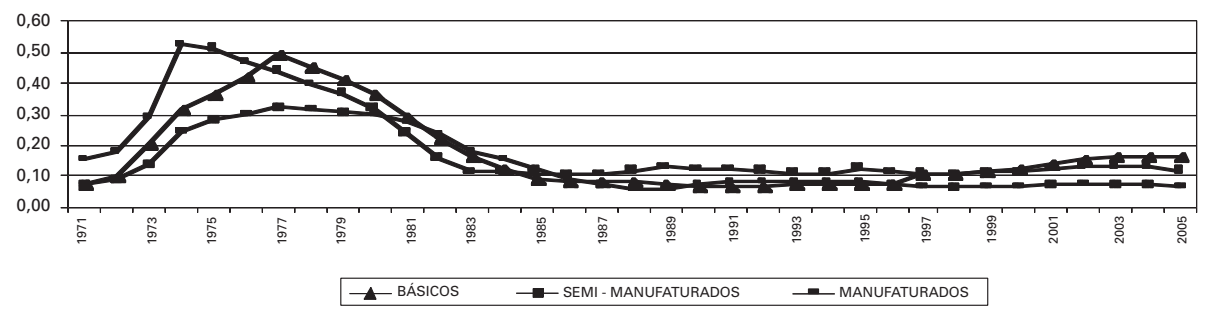

Tabela 1: Taxas de crescimento do quantum exportado pelo Brasil

\begin{tabular}{lcccc}
\hline Período & Agregado & Básicos & Semi-manufaturados & Manufaturados \\
\hline $1964-1974$ & $10,0 \%$ & $6,7 \%$ & $7,1 \%$ & $25,0 \%$ \\
\hline $1964-1981$ & $8,2 \%$ & $3,6 \%$ & $8,7 \%$ & $21,1 \%$ \\
\hline $1964-2005$ & $6,7 \%$ & $4,1 \%$ & $8,8 \%$ & $10,9 \%$ \\
\hline $1974-1981$ & $7,8 \%$ & $1,9 \%$ & $13,7 \%$ & $16,7 \%$ \\
\hline $1981-1989$ & $5,1 \%$ & $1,0 \%$ & $12,1 \%$ & $6,4 \%$ \\
\hline $1989-2005$ & $7,0 \%$ & $8,0 \%$ & $6,3 \%$ & $6,9 \%$ \\
\hline
\end{tabular}

Taxas calculadas ajustando-se uma reta aos logaritmos dos índices.

Tabela 2: Resultados do Modelo de Market Share Constante para 1964/65-1973/74 (US\$ milhões)

\begin{tabular}{lrrrrcc}
\hline $\begin{array}{l}\text { Exportações por } \\
\text { fator agregado }\end{array}$ & $\begin{array}{l}\text { Efeito } \\
\text { total }\end{array}$ & $\begin{array}{l}\text { Efeito (Paasche) } \\
\text { competitividade }\end{array}$ & $\begin{array}{l}\text { Efeito } \\
\text { produto }\end{array}$ & $\begin{array}{l}\text { Efeito } \\
\text { demanda }\end{array}$ & $\begin{array}{l}\text { Efeito (Laspeyres) } \\
\text { competitividade }\end{array}$ & $\begin{array}{l}\text { Efeito Adaptação } \\
\text { relativa }\end{array}$ \\
\hline Básicos & $-636,2$ & $1.836,3$ & $-2.472,5$ & $3.869,3$ & 458,2 & $1.378,1$ \\
\hline $\begin{array}{l}\text { Semi- } \\
\text { manufaturados }\end{array}$ & 68,8 & 163,5 & $-94,7$ & 411,1 & 52,5 & 110,9 \\
\hline Manufaturados & $1.402,4$ & $1.401,6$ & 0,8 & 320,8 & 336,9 & $1.064,7$ \\
\hline $\begin{array}{l}\text { Transações } \\
\text { especiais }\end{array}$ & 102,6 & 116,5 & $-13,9$ & 23,7 & 51,4 & 65,1 \\
\hline Não classificados & $-0,2$ & $-0,1$ & $-0,1$ & 0,1 & 0,0 & $-0,1$ \\
\hline TOTAL & 937,4 & $3.517,7$ & $-2.580,3$ & $4.625,0$ & 898,9 & $2.618,8$ \\
\hline
\end{tabular}

